Received: June 27, 2017

Accepted after revision: January 15, 2018

Published online: March 14, 2018

\title{
Altered Hippocampal Gene Expression and Morphology in Fetal Piglets following Maternal Respiratory Viral Infection
}

\author{
Adrienne M. Antonson ${ }^{\mathrm{a}}$ Bindu Balakrishnan ${ }^{\mathrm{a}}$ Emily C. Radlowski ${ }^{\mathrm{a}}$ \\ Geraldine Petr $^{\mathrm{a}}$ Rodney W. Johnson ${ }^{\mathrm{a}-\mathrm{c}}$ \\ ${ }^{a}$ Department of Animal Sciences, Laboratory of Integrative Immunology and Behavior, University of Illinois \\ Urbana-Champaign, Urbana, IL, USA; ${ }^{b}$ Division of Nutritional Sciences, University of Illinois Urbana-Champaign, \\ Urbana, IL, USA; ${ }^{C}$ Neuroscience Program, University of Illinois Urbana-Champaign, Urbana, IL, USA
}

\section{Keywords}

Maternal immune activation · Prenatal insult .

Microglia · Hippocampus · Neurogenesis · Fetal pig ·

Neuroinflammation

\begin{abstract}
Maternal infection during pregnancy increases the risk of neurobehavioral problems in offspring. Evidence from rodent models indicates that the maternal immune response to infection can alter fetal brain development, particularly in the hippocampus. However, information on the effects of maternal viral infection on fetal brain development in gyrencephalic species is limited. Thus, the objective of this study was to assess several effects of maternal viral infection in the last one-third of gestation on hippocampal gene expression and development in fetal piglets. Pregnant gilts were inoculated with porcine reproductive and respiratory syndrome virus (PRRSV) at gestational day (GD) 76 and the fetuses were removed by cesarean section at GD 111 (3 days before anticipated parturition). The gilts infected with PRRSV had elevated plasma interleukin- 6 levels and developed transient febrile and anorectic responses lasting approximately 21
\end{abstract}

\section{KARGER}

(c) 2018 S. Karger AG, Basel

E-Mail karger@karger.com

www.karger.com/dne days. Despite having a similar overall body weight, fetuses from the PRRSV-infected gilts had a decreased brain weight and altered hippocampal gene expression compared to fetuses from control gilts. Notably, maternal infection caused a reduction in estimated neuronal numbers in the fetal dentate gyrus and subiculum. The number of proliferative Ki$67+$ cells was not altered, but the relative integrated density of GFAP+ staining was increased, in addition to an increase in GFAP gene expression, indicating astrocyte-specific gliosis. Maternal viral infection caused an increase in fetal hippocampal gene expression of the inflammatory cytokines TNF- $\alpha$ and IFN- $\gamma$ and the myelination marker myelin basic protein. MHCll protein, a classic monocyte activation marker, was reduced in microglia, while expression of the MHCII gene was decreased in hippocampal tissue of the fetuses from PRRSV-infected gilts. Together, these data suggest that maternal viral infection at the beginning of the last trimester results in a reduction in fetal hippocampal neurons that is evident 5 weeks after infection, when fetal piglets are near full term. The neuronal reduction was not accompanied by

A.M. Antonson and B. Balakrishnan contributed equally to this work.

Rodney W. Johnson

116 Animal Sciences Laboratory, University of Illinois Urbana-Champaign 1207 W. Gregory Drive

Urbana, IL USA 61801 (USA)

E-Mail rwjohn@illinois.edu 
pronounced neuroinflammation at GD 111, indicating that any activation of classic neuroinflammatory pathways by maternal viral infection, if present, is mostly resolved by parturition.

(C) 2018 S. Karger AG, Basel

\section{Introduction}

Epidemiological studies have linked prenatal maternal infections, both viral and bacterial, to structural and functional brain abnormalities postnatally $[1,2]$. It is speculated that activation of the maternal immune system can lead to changes in the maternal-fetal cytokine balance, ultimately altering fetal brain development $[3,4]$. The third trimester in human pregnancy represents a critical window for both fetal brain and immune system development, and is characterized by neural migration, apoptosis, synaptogenesis, myelination, and immune cell colonization $[5,6]$. Neurons and glia in the developing brain have numerous cytokine receptors and are sensitive to inflammatory conditions $[7,8]$. Indeed, animal models of maternal immune activation (MIA) have demonstrated that offspring develop symptoms reminiscent of neuropsychiatric or neurological disorders, such as autism, schizophrenia, and epilepsy [9-12].

Numerous studies support the concept that maternal cytokines signal across the maternal-fetal interface and drive MIA outcomes. Smith et al. [13] demonstrated, through inhibition or injection of recombinant IL-6 into pregnant dams, the critical involvement of this particular cytokine in mediating behavioral abnormalities in murine offspring. A potential mechanism through which IL-6 accesses the fetal compartment was revealed by $\mathrm{Wu}$ et al. [14], who performed a restricted deletion of the IL-6 receptor on placental trophoblasts to prevent the neurodevelopmental pathologies caused by MIA. In the brain of fetuses exposed to maternal lipopolysaccharide (LPS) treatment, intracellular IL-6 signaling, through signal transducer and activator of transcription 3 (STAT3), is increased and can be blunted by IL-6-blocking antibody [14, 15]. A series of elegant studies done in a rodent maternal polyinosinic:polycytidylic acid (poly I:C) model revealed that IL-6 may also be driving T-helper-cell development and activation, augmenting IL-17a release [16]. This group has demonstrated that IL-17a is sufficient to produce abnormal cortical development [17] and autism-like phenotypes [18] in offspring, and that these phenotypes can be prevented by blocking $\mathrm{T}$ helper 17 cells or by administration of IL-17a-blocking antibody in pregnant dams [19].
Investigations into the involvement of microglia in MIA mechanisms are of interest [5] due to the fact that these resident CNS immune cells are the primary responders to cytokine signaling in the brain and are involved in neurodevelopmental pathologies [20-23]. Microglia begin colonizing the brain during early gestation $[24,25]$ and aid in healthy neurodevelopment by producing neurotrophic factors and by phagocytosing excess cells and synapses [24-29]. Currently, studies determining the role of fetal microglia in MIA are conflicting; though Cunningham et al. [24] demonstrated that activated microglia in a maternal LPS model deplete the fetal neural progenitor pool by excessive phagocytosis, Smolders et al. [30] failed to find any activation of fetal microglia due to maternal poly I:C treatment at embryonic day (E) 11.5 or double injection at E11.5 and E15.5. Pratt et al. [31], however, demonstrated that the same dose of poly I:C administered at E12.5 resulted in an increased production of several proinflammatory cytokines and chemokines by fetal microglia, while the total number of microglia was unchanged. These studies indicate that microglial cell activation in MIA is dependent on the timing and nature of the maternal insult, and that the answer to whether fetal microglia are involved in MIA etiology is still not clear.

The evidence does suggest, however, that the hippocampus, a region of the brain important for learning and memory, may be particularly vulnerable to maternal insults. Zhang and van Praag [32] demonstrated that maternal treatment with poly I:C results in reduced dentate gyrus volume and differential firing properties of hippocampal neurons in neonatal offspring, resulting in an impaired spatial navigational ability. Pineda et al. [10] showed that altered maternal cytokine levels during pregnancy can change the intrinsic property of hippocampal neurons in the offspring. A rise in maternal proinflammatory cytokines such as IL- $1 \beta$ and IL- 6 increases hippocampal excitability in offspring, in turn increasing the susceptibility to seizures. Maternal poly I:C treatment has also been shown to decrease presynaptic proteins in offspring and impair long-term potentiation within the CA1-CA3 pathway [33]. Taken together, these data indicate that prenatal immune activation has the potential to permanently alter neuronal circuits within the hippocampus.

We sought to determine the impact of maternal viral infection on the neonatal hippocampus using a pig MIA model. The domestic piglet serves as an excellent model of early brain development due to its neurodevelopmental trajectories and anatomy, which align closely to that of 
humans [34-37]. Additionally, the gyrencephalic porcine brain undergoes a major growth spurt from the late prenatal to the early postnatal period, closely mimicking the accelerated brain growth and development that occurs in human infants $[35,38]$.

Here, we inoculated pregnant gilts with porcine reproductive and respiratory syndrome virus (PRRSV) at gestational day (GD) 76 and fetuses were removed by cesarean section at GD 111 (3 days before anticipated parturition). PRRSV infects porcine alveolar macrophages, leading to interstitial pneumonia [39]; the symptoms include anorexia, fever, and sometimes cyanosis [40], similar to what is observed with a human influenza infection [41]. Previous studies in our laboratory have shown that early postnatal PRRSV infection results in reduced neurogenesis and enhanced microglial activity in the neonatal hippocampus [42, 43], and that postnatal PRRSV infection impairs neonatal piglet performance in a hippocampus-dependent learning and memory task [44]. More recent evidence from our porcine MIA model demonstrates that prenatal exposure to maternal PRRSV infection causes altered social behaviors postnatally, while prolonged microglial activation is not evident [45]. Thus, we aimed to characterize the impact of MIA on hippocampal neurodevelopment and glial reactivity prenatally. We hypothesized that maternal PRRSV infection would alter fetal hippocampal development (decreasing neuron numbers) and that fetal microglial cells would display an activated phenotype. However, our results indicate that proinflammatory MHCII+ microglia are not more abundant at GD 111, though estimated neuronal cell density is indeed decreased in the dentate gyrus and subiculum, and fetal piglets exposed to maternal infection demonstrate GFAP-specific gliosis.

\section{Materials and Methods}

\section{Animals}

Eight pregnant crossbred (Large White/Landrace) gilts, PRRSV free and not vaccinated, were brought from the University of Illinois swine herd into the biomedical animal facility at GD 69. The gilts were housed individually in standard farrowing crates $(1.83 \times$ $1.83 \mathrm{~m}$ ) in identical disease containment chambers kept at $22^{\circ} \mathrm{C}$ and maintained on a $12-\mathrm{h}$ light/dark cycle. All gilts were provided with ad libitum access to water and $2.3 \mathrm{~kg}$ of a standard corn-soybean meal-based gestational diet daily (University of Illinois feed mill, Urbana-Champaign).

On GD 76, the gilts were inoculated intranasally with either 5 $\mathrm{mL}$ of $1 \times 10^{5} 50 \%$ tissue culture infected dose of live PRRSV (strain P129-BV, obtained from the School of Veterinary Medicine at Purdue University, West Lafayette, IN, USA) or sterile phosphatebuffered saline (PBS) (PRRSV: $n=4$; controls: $n=4$ ). PRRSV is an enveloped single-stranded RNA virus which causes interstitial pneumonia by infecting alveolar macrophages [39], and results in increased secretion of IL- $1 \beta$, IL- 6 , and TNF- $\alpha[46,47]$. Rectal temperature and feed intake were monitored daily. Blood was collected from the marginal ear vein once weekly, on GD 76 (immediately before PRRSV inoculation), GD 83, GD 90, GD 97, and GD $104(0,7,14,21$, and 28 days post infection [dpi], respectively).

On GD 111 (35 dpi), the gilts were anesthetized using a Telazol:ketamine:xylazine drug cocktail (50 mg of tiletamine plus $50 \mathrm{mg}$ of zolazepam reconstituted with $2.5 \mathrm{~mL}$ ketamine [100 g/L] and $2.5 \mathrm{~mL}$ xylazine [100 g/L]; Fort Dodge Animal Health, Fort Dodge, IA, USA) administered intravenously through the marginal ear vein at $0.005 \mathrm{~mL} / \mathrm{kg}$ body weight. They were then euthanized via intravenous injection of sodium pentobarbital $(86 \mathrm{mg} / \mathrm{kg}$ body weight; Fatal Plus; Vortech Pharmaceutical, Dearborn, MI, USA) and placed in a lateral recumbent position on an operating table once euthanasia was confirmed. A 3- to 4 -inch midline incision was made at the lower abdomen and the uterine horns were exposed. The individual fetuses were carefully removed and the preservation for each fetus was recorded as "viable" (healthy before euthanasia) or "nonviable" (evidence of decomposition; these fetuses were counted but not included in the analyses). The umbilical artery of each viable fetus was severed and blood was collected in blood collection tubes containing clot activator or EDTA. The blood tubes were allowed to clot at room temperature for $30 \mathrm{~min}$ and then centrifuged $\left(1,300 \mathrm{~g}\right.$ at $4^{\circ} \mathrm{C}$ for $\left.15 \mathrm{~min}\right)$, and serum and plasma were collected and stored at $-80^{\circ} \mathrm{C}$. The body and brain weights of each fetus were recorded. The right hippocampus was immediately dissected out and placed in Hanks' balanced salt solution (without calcium and magnesium; Mediatech, Inc., Manassas, VA, USA) for microglial cell isolation. The left hippocampus was divided into two halves; the dorsal half was frozen on dry ice for analysis of gene expression and the ventral half was placed in $4 \%$ paraformaldehyde for immunohistochemistry.

All animal care and experimental procedures were in accordance with the National Research Council Guide for the Care and Use of Laboratory Animals and approved by the University of Illinois Institutional Animal Care and Use Committee.

\section{Microglial Cell Isolation and Flow Cytometry}

Microglial cells were isolated from hippocampal tissue based on positive expression of CD11b using the Miltenyi Biotec neural cell isolation procedure, as described previously [45]. Briefly, cell isolation was performed using Miltenyi Biotec Neural Tissue Dissociation Kits (P), CD11b (microglia) MicroBeads, and equipment (Miltenyi Biotec, San Diego, CA, USA) according to the manufacturer's instructions, with some modifications. Falcon cell strainers $(40 \mu \mathrm{m})$ were used in place of the $70-\mu \mathrm{m}$ strainers listed. Myelin removal was achieved by centrifugation with a $30 \%$ Percoll PLUS (GE Healthcare Life Sciences, Pittsburgh, PA, USA) solution in PBS.

The sample was incubated with CD11b (microglia) MicroBeads, then passed through MS columns and collected. The final $\mathrm{CD} 11 \mathrm{~b}+$ fraction was centrifuged at $300 \mathrm{~g}$ for $10 \mathrm{~min}$ at $4{ }^{\circ} \mathrm{C}$. The isolated cells were then resuspended in flow buffer (PBS with $1 \%$ BSA [Thermo Fisher Scientific], 0.1\% sodium azide [Sigma-Aldrich], and $20 \mathrm{~mm}$ glucose [Sigma-Aldrich]). Competitive binding of the Fc receptor was blocked with purified CD16/CD32 antibodies (eBioscience, San Diego, CA, USA). The cells were incubated with CD11b antibodies (BioLegend, San Diego, CA, USA) to con- 
Table 1. Quantitative real-time PCR primer information

\begin{tabular}{lll}
\hline Gene & Classification & Assay identification ${ }^{\mathrm{a}}$ \\
\hline 18S rRNA, 18S ribosomal RNA & Reference & Hs99999901_s1 \\
RPL19, ribosomal protein L19 & Reference & Ss03375624_g1 \\
TNF- $\alpha$ & Proinflammatory & Ss03391318_g1 \\
TLR3 & Viral & Ss03388861_m1 \\
TGF- $\beta$ & Anti-inflammatory & Ss03382325_u1 \\
SYP, synaptophysin ${ }^{\text {b }}$ & Neuronal & Custom \\
STAT3, signal transducer and activator of transcription 3 & Proinflammatory & Ss03388426_m1 \\
NTRK3, neurotrophic receptor tyrosine kinase 3 & Neuronal & Ss03394533_m1 \\
NTF3, neurotrophin 3 & Neuronal & Ss03387837_u1 \\
NGF, nerve growth factor & Neuronal & Custom \\
NF- $k B 1$ & Proinflammatory & Ss03388575_m1 \\
MHCII, major histocompatibility complex class II & Proinflammatory & Ss03389942_m1 \\
MBP, myelin basic protein & Neuronal & Ss03385047_u1 \\
IL-10 & Anti-inflammatory & Ss03382372_u1 \\
IL-6 & Proinflammatory & Ss03384604_u1 \\
IL-1 $\beta$ & Proinflammatory & Ss03393804_m1 \\
IFN- $\gamma$ & Proinflammatory & Ss03391054_m1 \\
HSP70, heat shock protein 70 & Oxidative stress & Ss03387784_u1 \\
GFAP, glial fibrillary acidic protein & Glial & Ss03373547_m1 \\
CX ${ }_{3}$ CL1, fractalkine & Neuronal & Ss03377157_u1 \\
CD200, cluster of differentiation 200 & Neuronal & Ss03375826_u1 \\
CD200R, receptor for CD200 & Microglial & Custom \\
CCL2, chemokine (C-C motif) ligand 2 & Proinflammatory & Ss03394377_m1 \\
BDNF, brain-derived neurotrophic factor & Neuronal & Ss03822335_s1 \\
\hline
\end{tabular}

${ }^{\mathrm{a}}$ Applied Biosystems TaqMan Gene Expression Assay identification number. ${ }^{\mathrm{b}}$ Synaptophysin custom probe: forward primer, GGCCAAGGACGGCTCAT; reverse primer, TTTTCCGCCCTTAGCATGTAG; probe, CAAGATTAAATGGTACGTAGGAC. ${ }^{\mathrm{c}}$ Nerve growth factor custom probe: forward primer, TCAACAGGACTCACAGGAGCAA; reverse primer, ACTCCCCCCGGTGGAAA; probe, CGGTCGTCATCCC. ${ }^{\mathrm{d}}$ CD200R custom probe: forward primer, TGTTCCAAGTTACTAATCAGGCTGAA; reverse primer, AGCCCATTAGCAACATGATACTCTTT; probe, ACATAGAATTGAAGGAAGGG.

firm CD11b+ selection, CD45 antibodies (AbD Serotec, Raleigh, NC, USA) to distinguish microglial cells from monocytes, and MHCII (antibodies-online, Atlanta, GA, USA) as a marker of phagocytic cell activation.

The cells were flowed through the FACSAria II flow cytometer (BD Biosciences, San Jose, CA, USA) and gated based on the forward and side scatter and autofluorescence properties of a massed unstained control sample. The cells were confirmed as CD11b+ microglial cells by intermediate expression of CD45 (as previously described $[44,45])$. Thus, cells that were CD11b+CD45 low-int and MHCII+ were considered to be activated microglia. FACSDiva software (BD Biosciences) was used to analyze the flow cytometry data.

\section{PRRSV and Cytokine Detection}

The presence of PRRSV in the serum of all gilts and fetuses was analyzed by the Veterinary Diagnostic Laboratory (University of Illinois, Urbana, IL, USA) using RT-PCR. Porcine DuoSet ELISA kits (R\&D Systems, Minneapolis, MN, USA) for IL-6, IL-10, and TNF- $a$ were used, according to the manufacturer's instructions, to quantify cytokines in maternal and fetal plasma.
Quantitative Real-Time PCR

Total RNA was extracted from the hippocampus of each fetus using the E.Z.N.A. Total RNA kit II (Omega Bio-Tek, Norcross, GA, USA) and cDNA was synthesized using a QuantiTect Reverse Transcription Kit (Qiagen, Valencia, CA, USA). Quantitative realtime PCR was performed using the Applied Biosystems TaqMan Gene Expression Assay protocol. The custom TaqMan Low Density Array card consisted of 384 wells and is preloaded with TaqMan gene expression assays that will detect real-time amplifications and user-defined targets. Two reference genes (18S ribosomal RNA [18S rRNA] and ribosomal protein L19 [RPL19]) and 22 genes of interest (Table 1) were used. Simultaneous amplification of target cDNA and reference cDNA was obtained using an oligonucleotide probe with a $5^{\prime}$ fluorescent reporter dye (6-FAM) and a $3^{\prime}$ quencher dye (NFQ). The PCR conditions included $50^{\circ} \mathrm{C}$ for $2 \mathrm{~min}, 95^{\circ} \mathrm{C}$ for $10 \mathrm{~min}, 40$ cycles at $95^{\circ} \mathrm{C}$ for $15 \mathrm{~s}$, and 1 cycle at $60^{\circ} \mathrm{C}$ for $1 \mathrm{~min}$.

Relative gene expression was determined from the fluorescence data using the ABI PRISM 7900HT Sequence Detection System (PerkinElmer, Waltham, MA, USA). Thirty-one representative fetuses, from 2-3 litters per group, were analyzed, and each sample
Antonson/Balakrishnan/Radlowski/Petr/ Johnson 


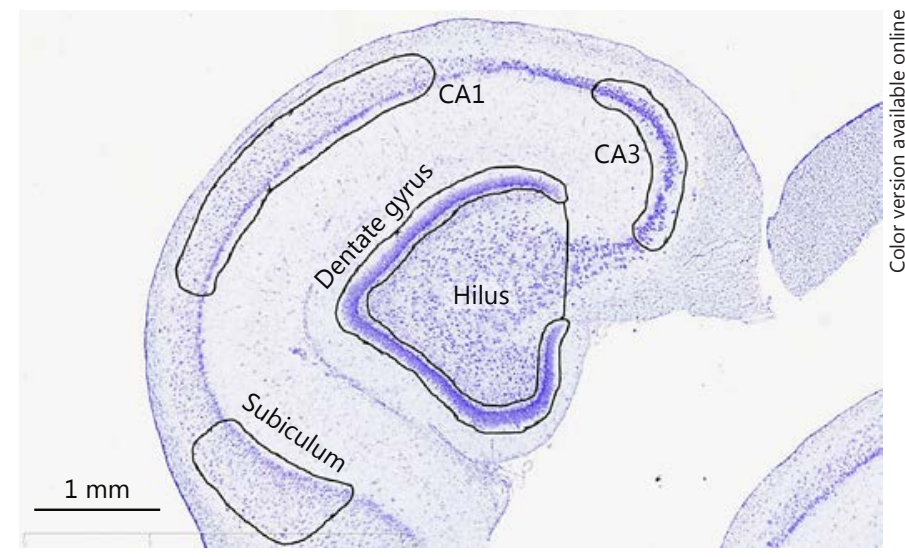

Fig. 1. Representative image of cresyl violet-stained cells in the fetal hippocampus, demonstrating the regions of interest selected for analyses (subiculum, CA1, CA3, dentate gyrus, and hilus).

was run in duplicate. The data were analyzed using the comparative threshold (Ct) cycle method [48], and the results are expressed as fold change to the standardized relative quantification baseline (relative quantification $=1$ ), whereby a value $>1$ would represent a fold increase in mRNA expression compared to the control, and a value between 0 and 1 would represent a fold decrease in mRNA expression. The data were normalized to the internal control RPL19.

The data exclusion criteria were as follows: (1) both wells were below the detection limit (undetermined $\mathrm{Ct}$ ) or (2) the values were above or below the upper or lower fence of the distribution, respectively (see the outlier exclusion criteria in the Statistical Analysis subsection below). There was a significant (or trending) effect of sex, but not maternal treatment, on three genes; in this case, as there was no sex $\times$ treatment interaction, maternal treatment was removed from the model.

\section{Cresyl Violet Staining}

Ten-micrometer hippocampal sections, $100 \mu \mathrm{m}$ apart, were stained with $1 \%$ cresyl violet. Paraffin-embedded brain sections were dewaxed in xylene, rehydrated with $100 \%$ alcohol, and stained with $1 \%$ cresyl violet (Sigma-Aldrich) for 4-5 min. Excess stain was rinsed in tap water, after which the slides were washed in $70 \%$ alcohol and dehydrated through absolute alcohol. The sections were cleared in xylene, mounted with DPX Mounting Medium (Sigma-Aldrich), coverslipped, and allowed to air-dry under a fume hood [49]. The exclusion criteria were (1) variable staining intensity, i.e., either too dark or too light, or (2) slide or tissue section damage.

\section{Estimated Neuronal Cell Counts}

The cresyl violet-stained sections were scanned on a NanoZoomer (Hamamatsu Photonics, Hamamatsu, Japan) slide scanner at $40 \times$ magnification. The images were exported to $20 \times$, and the CA1, CA3, and subiculum regions were manually traced using the free hand tool in ImageJ; then the number of cells within those regions were counted. A representative image of the traced regions of the hippocampus is shown in Figure 1. The CA1, CA3, and subiculum regions were identified by the location and size of cells. Pyramidal cells in the CA3 region were in the angle of the "C" shape of the tissue and were large and tightly arranged; CA1 cells were located in the top peak region of the " $\mathrm{C}$ " and were smaller in size. This CA1 region was selected to avoid overlapping with the CA2 region. The cells in the subiculum were loosely arranged and were located at the rear end of the " $\mathrm{C}$ " region. The hilar region was identified as the region immediately below the dentate gyrus. Neurons within each traced region were counted, and the values are expressed as the number of cells $/ \mathrm{mm}^{2}$. All cell counting was performed by an experimenter who was blinded to the treatments.

Due to the large number of cells in the dentate gyrus and their compact arrangement, the relative integrated density of cells in this region was estimated using ImageJ. Here, the images were converted to 16 bit and the region of the dentate gyrus was traced using the free hand tool. Five different regions along the dentate gyrus that were devoid of any cells were selected to subtract the background. The relative integrated density was calculated as the mean integrated density of positive staining in the region of interest minus the nonstained background integrated intensity. The integrated density is the sum of the values of pixels in a region of interest and can be used to measure the density of positively stained cells [50-53].

Representative piglets from each group $(n=11-17)$ were selected for cresyl violet analysis, and each group was balanced for sex and body weight. Only piglets whose body weight was within the range of $1.0-1.6 \mathrm{~kg}$ were included in the analysis to prevent the confounding effect of small-for-gestational-age body weight. Our group has previously reported that being small for gestational age can increase the risk of impaired cognitive processing in piglets [54]. Four to 6 separate tissue sections were analyzed per piglet and then averaged.

\section{GFAP and Ki-67 Immunostaining}

Ten-micrometer paraffin-embedded sections were mounted onto slides. The sections were dewaxed, hydrated using different grades of alcohol, and washed with PBS. Following antigen retrieval in citrate buffer, the sections were blocked with $3 \%$ hydrogen peroxide to remove endogenous peroxidase activity. Nonspecific staining was blocked using $2 \%$ normal goat serum containing $0.3 \%$ Triton X-100 and incubated in primary anti-GFAP antibody (1: 100; Santa Cruz Biotechnology, Santa Cruz, CA, USA) overnight at $4{ }^{\circ} \mathrm{C}$ or anti Ki-67 antibody (1:100; BD Pharmingen, San Jose, CA, USA) for $48 \mathrm{~h}$ at $4^{\circ} \mathrm{C}$. The next day, the sections were washed and incubated in biotinylated secondary antibody (1:200; goat anti-mouse antibody; Jackson ImmunoResearch Laboratories, West Grove, PA, USA) followed by signal amplification using avidinbiotin complex (ABC reagent; Vector Laboratories, Burlingame, CA, USA). Color was developed using a diaminobenzidine kit (Vector Laboratories). The exclusion criteria were identical to those described above for cresyl violet staining.

\section{Quantification of GFAP+ and Ki-67+ Cells}

GFAP- and Ki-67-stained sections were scanned using a NanoZoomer (Hamamatsu Photonics) under $20 \times$ magnification. The images were exported to ImageJ. Each image was converted to 16 bit and the hilar region was traced using the free hand tool. The relative integrated density of GFAP staining was calculated as described above. 
Fig. 2. Porcine reproductive and respiratory syndrome virus (PRRSV) inoculation resulted in transient febrile and anorectic responses in the gilts, and increased IL- 6 in plasma. Rectal temperature $(\mathbf{A})$ and food intake (B) were recorded daily in the controls $(n=4)$ and PRRSV-inoculated gilts $(n=4)$. Arrows: inoculation with sterile saline or PRRSV. A significant treatment $x$ day interaction revealed an increased body temperature $(p<0.01)$ and decreased food intake $(p<0.05)$ in the gilts inoculated with PRRSV. C The plasma IL- 6 concentration at 7 days post infection was increased in the PRRSV-inoculated gilts (gestational day 83; $p<0.05$; controls: $n=3$; PRRSV: $n=4$ ). Data are represented as means \pm SEM. A, B Bonferroni post hoc tests: ${ }^{*} p<0.05$. C Student $t$ test: ${ }^{*} p<0.05$. D Maternal viral infection resulted in a decreased fetal brain weight compared to the controls. The fetuses from the PRRSV-infected gilts ( $n=$ 32) had a decreased brain weight compared to the fetuses from the control gilts $(n=47$; $p<0.05)$. Data are represented as means \pm SEM. ${ }^{*} p<0.05$.
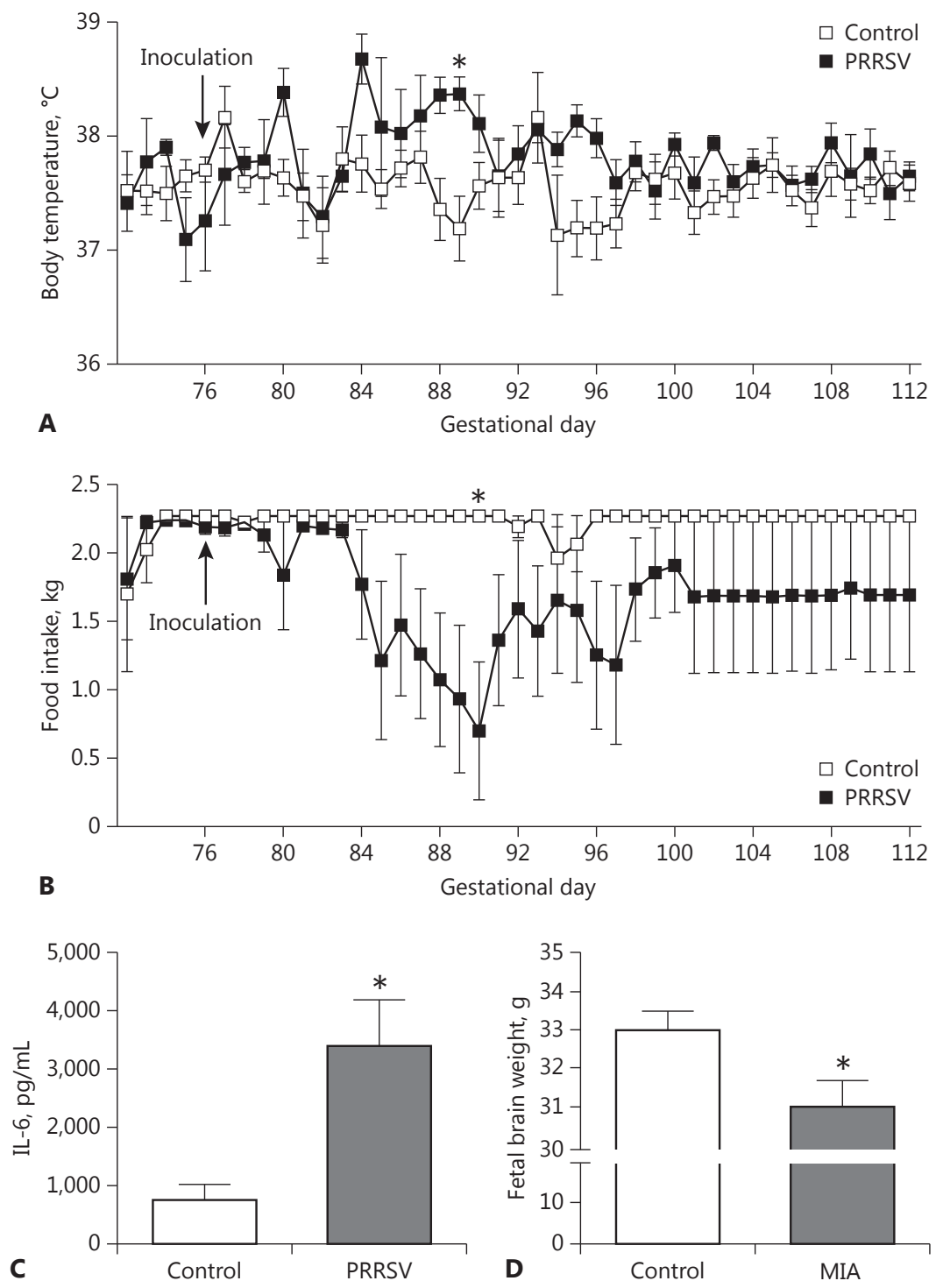

For Ki-67+ cell counts, two regions of interest were selected: the dentate gyrus (consisting of the suprapyramidal blade, infrapyramidal blade, and subgranular zone) and the hilar region. An automated cell analysis plugin in ImageJ was used to count the number of positive cells in these two regions of interest. The total number of Ki-67+ cells is expressed as the number of cells $/ \mathrm{mm}^{2}$.

For each stain, 4-6 separate tissue sections were analyzed per piglet and then averaged. Seven to 11 representative piglets per group were included, and each group was balanced for sex and body weight.

\section{Statistical Analysis}

Statistical analyses were carried out using GraphPad Prism (GraphPad Software, Inc., La Jolla, CA, USA) or Statistical Analysis Software (SAS Institute, Cary, NC, USA). For all comparisons, $\alpha$ was set at 0.05 and the data are expressed as means \pm SEM. The current study was not designed to reveal significant sex effects and is therefore underpowered for these analyses. Even so, all initial tests were run with sex included in the model. We found that there was no significant effect of sex in most analyses, so this variable was removed from those models.

Outliers were identified using the SAS code "proc boxplot, boxstyle = schematicid," which identifies variables beyond the fences (beyond the 3rd or 1st quartile plus or minus 1.5 times the interquartile range, respectively); all outliers were removed before statistical testing was performed. Two-way repeated-measures analysis of variance (ANOVA; treatment $\times$ day) was used for rectal temperature and feed intake in gilts. Bonferroni post hoc tests were performed for two-way ANOVA comparisons with significant main effects or interactions. One-way ANOVAs were used for 
Table 2. Average litter characteristics

\begin{tabular}{llll}
\hline $\begin{array}{l}\text { Treatment } \\
\text { group }\end{array}$ & $\begin{array}{l}\text { Litter } \\
\text { size }\end{array}$ & $\begin{array}{l}\text { Viable } \\
\text { piglets }\end{array}$ & $\begin{array}{l}\text { Nonviable } \\
\text { piglets }\end{array}$ \\
\hline Control $(n=4)$ & $12.8 \pm 1.5$ & $12.5 \pm 1.3$ & $0.3 \pm 0.3$ \\
PRRSV $(n=4)$ & $11.3 \pm 1.3$ & $8.3 \pm 0.5^{*}$ & $3.0 \pm 1.6^{*}$ \\
\hline$p$ value & ns & 0.023 & 0.048 \\
\hline
\end{tabular}

Data are means \pm SEM. The authors would like to note that the current study was not designed to detect significant litter differences due to maternal PRRSV infection and thus is underpowered for those analyses. These data are merely meant to summarize the average characteristics of the litters used in the study. PRRSV, porcine reproductive and respiratory syndrome virus; ns, nonsignificant. ${ }^{*} p<0.05$.

analysis of piglet brain weight, body weight, gene expression, hippocampal estimated neuronal cell counts, and flow cytometry data.

A Student $t$ test was used to analyze the IL- 6 concentration in gilts. In the current study, each piglet was considered an experimental unit, as pigs are a multiparous species where each fetus has an individual fetal system, and it is plausible that piglets within the same litter would present with varied responses to maternal infection [55]. Positive PRRSV infection was included in all statistical tests, but it did not impact any measures, and thus PRRSV+ fetuses are equally represented in all analyses.

\section{Results}

\section{Clinical Signs and Infection Status of}

PRRSV-Inoculated Pregnant Gilts

PRRSV infection caused an increase in gilt rectal temperature (treatment $\times$ day, $p<0.01$; Fig. $2 \mathrm{~A}$ ) and a decrease in gilt food intake (treatment $\times$ day, $p<0.05$; Fig. 2B). The PRRSV-inoculated gilts had increased levels of plasma IL- 6 at 7 dpi ( $p<0.05$; Fig. 2 C).

The RT-PCR analysis of maternal serum at 7, 14, 21, and 28 dpi confirmed that the PRRSV-inoculated gilts were positive for the virus 1 week after inoculation and throughout the remainder of the study, except for 1 PRRSV-inoculated gilt, who was positive at 7,14 , and 21 dpi but negative at $28 \mathrm{dpi}$. Serum from all 4 control gilts tested negative for PRRSV throughout the study, and all 8 gilts tested negative at $0 \mathrm{dpi}$ (data not shown).

\section{Maternal PRRSV Infection Decreased Fetal Brain \\ Weight but Did Not Impact Fetal Body Weight}

Fifty-one fetuses were obtained from the 4 saline control gilts, and 45 fetuses from the 4 PRRSV-inoculated gilts (the litter characteristics are summarized in Table 2).
A total number of 1 and 12 nonviable fetuses were obtained from the control and PRRSV-inoculated gilts, respectively, which were excluded from the study (thus, 50 control fetuses and 33 fetuses from PRRSV gilts were included in the study). There was a main effect of maternal PRRSV infection on the number of viable and nonviable piglets obtained from each group $(p<0.05$; Table 2$)$. Fetal body weights were similar between the treatment groups (controls: $1.19 \pm 0.05 \mathrm{~kg}$; MIA: $1.16 \pm 0.05 \mathrm{~kg} ; p=0.619$ ), indicating that PRRSV-induced anorexia did not affect overall fetal growth. Unsurprisingly, there was a trending effect of sex $(p=0.0693)$ and a main effect of litter size $(p<0.0001)$ on fetal body weight. The fetuses from PRRSV-inoculated gilts had decreased brain weights compared to the controls ( $p<0.05$; Fig. 2D), which may indicate an underlying neurodevelopmental pathology due to maternal viral infection. Litter size and sex did not affect brain weight.

\section{Cytokine Concentrations in Cord Blood Were below \\ Detectable Levels}

Plasma IL-6, IL-10, and TNF- $\alpha$ concentrations were measured in cord blood collected from all viable fetal piglets immediately following extraction from the uterus. The concentrations were below detectable levels for all three cytokines.

\section{Maternal Infection Did Not Increase Fetal Microglial MHCII Expression}

Enriched CD11b+ microglia expressed CD45 at low levels, indicating that they were microglia and not monocytes [56-58]. GD 111 fetal microglia expressed MHCII at very low levels (control: $0.73 \pm 0.06 \%$; MIA: $0.36 \pm$ $0.08 \%$ ). There was a decrease in the percentage of microglia expressing MHCII in the prenatal infection group $(p<$ 0.001 ), though it is uncertain whether this is physiologically relevant.

\section{Fetuses from PRRSV-Infected Gilts Displayed Altered Hippocampal Gene Expression}

MIA upregulated relative TNF- $\alpha$ and IFN- $\gamma$ gene expression in the hippocampus $(p<0.001$ and $p<0.0001$, respectively) and tended to upregulate the expression of IL-1 $\beta(p=0.056)$ and STAT3 $(p=0.079)$. The expression of GFAP $(p<0.001)$ and myelin basic protein (MBP; $p<$ $0.05)$ was upregulated in the MIA fetuses, while MHCII expression was downregulated $(p<0.001)$, indicative of gliosis that is specific to GFAP+ cells. Maternal infection tended to upregulate CD200 expression $(p=0.077)$, while CD200R expression was unchanged. The results for all 22 


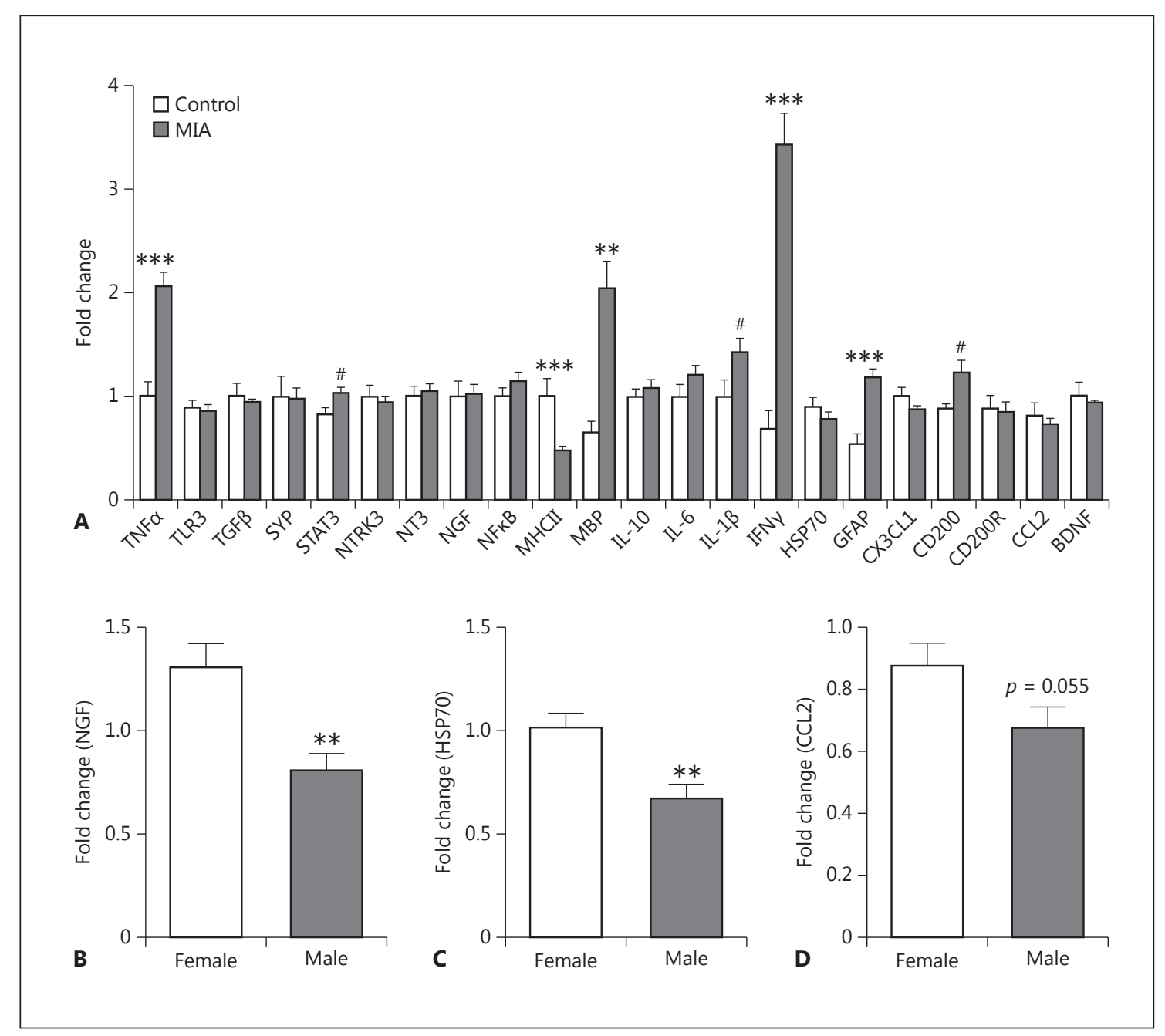

Fig. 3. A Prenatal exposure to maternal viral infection differentially regulates the expression of several inflammatory and neuron- or glia-associated genes in the fetal hippocampus. The male fetuses expressed less NGF (B; $p<$ $0.01)$ and HSP70 (C; $p<0.01)$ and tended to express less CCL2 (D; $p=0.055)$ compared to the females. Data are expressed as fold change \pm SEM. ${ }^{* * *} p<0.001,{ }^{* *} p<0.01$; ${ }^{*} p=0.08$. Controls: $n=7-9$; MIA: $n=15-22$ (except IFN- $\gamma: n=7$ per group). MIA, maternal immune activation.

genes are graphically represented in Figure $3 \mathrm{~A}$. The expression of nerve growth factor (NGF; $p<0.01$; Fig. 3B) and heat shock protein 70 (HSP70; $p<0.01$; Fig. 3C) was decreased in male fetuses compared to females, but there was no effect of maternal treatment. Males also tended to express less chemokine (C-C motif) ligand 2 (CCL2) than females ( $p=0.055$; Fig. 3D).

\section{Maternal Infection Decreased Neuronal Cell Density in the Fetal Dentate Gyrus and Subiculum}

While no significant difference was found between the numbers of neurons in the CA1 (controls: 1,890 \pm
235.6 cells $/ \mathrm{mm}^{2}$; MIA: $1,940 \pm 206.5$ cells $/ \mathrm{mm}^{2}$ ), CA3 (controls: $1,025 \pm 52.3$ cells $/ \mathrm{mm}^{2}$; MIA: $1,051 \pm 63.3$ cells $/ \mathrm{mm}^{2}$ ), and hilar (controls: $423.2 \pm 26.9$ cells $/ \mathrm{mm}^{2}$; MIA: $441.3 \pm 31.9$ cells $/ \mathrm{mm}^{2}$ ) regions of fetuses from PRRSV-inoculated gilts and the numbers of neurons in the respective regions of fetuses from control gilts $(p>$ 0.10 ), a reduction in the relative integrated density of cells located in the dentate gyrus of MIA fetuses was observed ( $p<0.001$; Fig. 4Aa, b, B). A similar reduction was observed in the number of neurons in the subiculum of fetuses from PRRSV-inoculated gilts $(p<0.001$; Fig. 4Ac, d, C). 


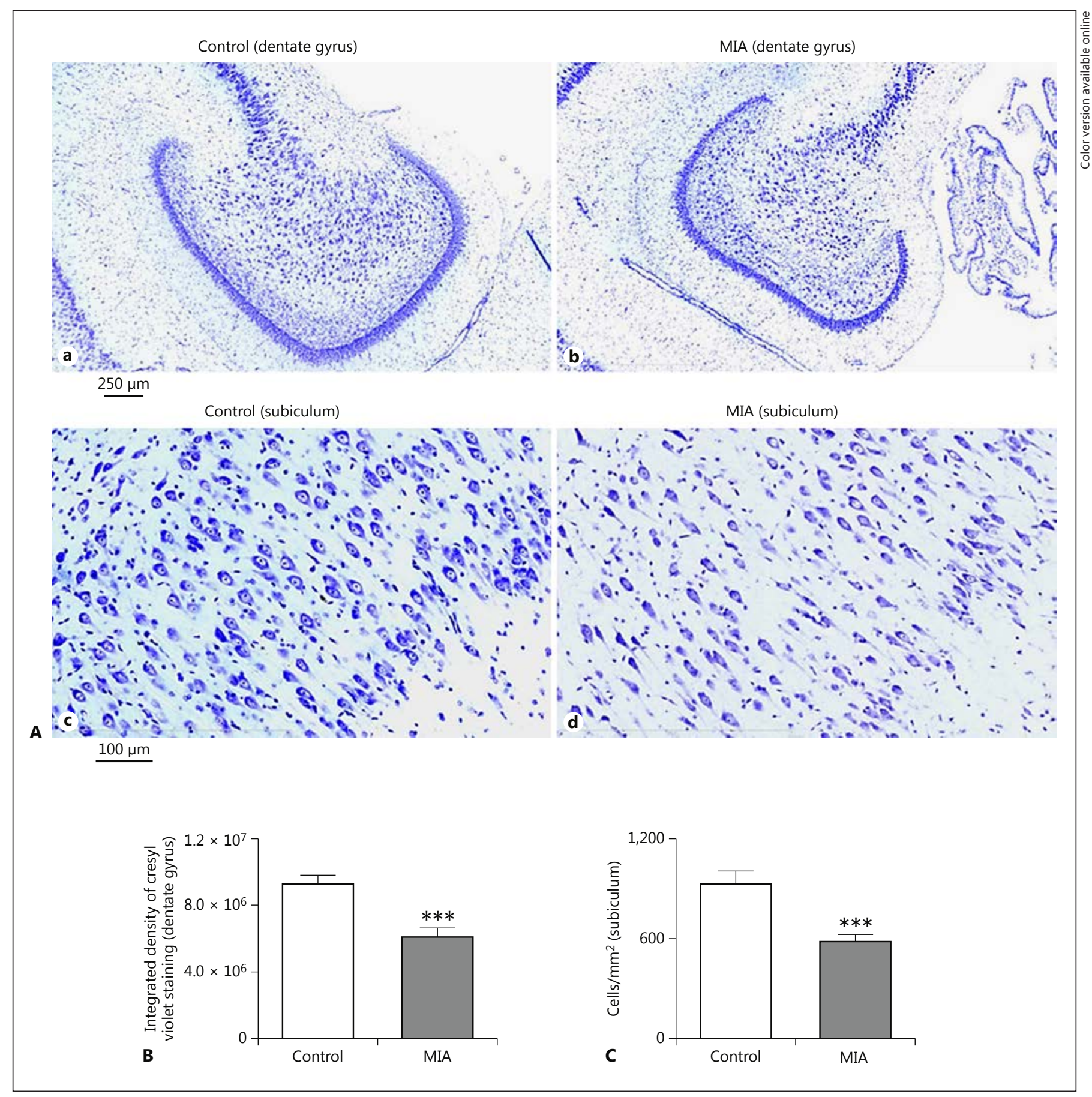

Fig. 4. Prenatal exposure to maternal viral infection resulted in a decreased neuronal number in the hippocampus. A Cresyl violetpositive cells in the dentate gyrus $(\mathbf{a}, \mathbf{b})$ and subiculum $(\mathbf{c}, \mathbf{d})$ of fetuses from control $(\mathbf{a}, \mathbf{c})$ and porcine reproductive and respiratory syndrome virus (PRRSV)-inoculated (b, d) gilts, respectively.
A decrease in the number of cresyl violet-stained neurons was observed in the dentate gyrus (B; $p<0.001)$ and subiculum $(\mathbf{C} ; p<$ 0.001 ) regions of the fetuses from PRRSV-infected gilts. Data are represented as means \pm SEM. ${ }^{* * *} p<0.001$. Controls: $n=11$; MIA: $n=14-17$. MIA, maternal immune activation. 
The Relative Integrated Density of GFAP+Cells, but Not the Number of Ki-67+Cells, Was Altered by Maternal Infection

To understand if the reduction in neuron number in the dentate gyrus and subiculum was due to decreased neuronal proliferation, we counted the number of proliferative cells (Ki-67+) in the dentate gyrus and hilus. However, the numbers of Ki-67+ cells were similar between the groups (dentate gyrus: controls $207 \pm 28.8$ cells $/ \mathrm{mm}^{2}$, MIA $171.1 \pm 24.3$ cells $/ \mathrm{mm}^{2}, p=0.354$; hilus: controls $52.1 \pm 7.4$ cells $/ \mathrm{mm}^{2}$, MIA $59.6 \pm 4.7$ cells $/ \mathrm{mm}^{2}, p=0.376$; controls: $n=9$; MIA: $n=14-15$ ).

Given that there was no change in the total number of proliferative cells in the hippocampus, we hypothesized that maternal infection was causing a greater number of differentiating cells to preferentially develop into glial cells rather than neurons. Thus, we quantified the relative integrated density of GFAP+ cells in the hilar region of the hippocampus. Indeed, the fetuses from PRRSV-infected gilts presented with an increased relative integrated density of GFAP+ cells compared to the control fetuses $(p<0.05$; Fig. 5$)$.

\section{Discussion}

In the present study, we demonstrated that late-gestation maternal PRRSV infection causes a reduction in fetal viability and brain weight, which is accompanied by decreases in the relative density of neurons, upregulation of GFAP-specific gliosis, and altered gene expression in the hippocampus. Hippocampal microglia did not appear to be activated and there were no differences in cell proliferation at GD 111, which leads us to suspect that fetal microglia is instead acutely activated by maternal viral infection, causing the observed alterations in hippocampal development, and that this activation is resolved by parturition. It is important to note that most of the existing literature on MIA is based on rodents, which differ from both pigs and humans in their anatomy and physiology and their innate immune responses [59-61]. It should be acknowledged that rodents are not always the ideal animal model for human diseases [62], and that certain immune parameters, as well as the neurodevelopmental timeline, are dissimilar between mice and pigs. To our knowledge, this is the first study to investigate the impact of maternal viral infection on fetal hippocampal neurons and glia in a gyrencephalic animal.

Maternal PRRSV infection resulted in febrile, anorectic, and inflammatory cytokine (IL-6) responses in preg- nant gilts after inoculation, and the presence of the virus in maternal serum was confirmed through RT-PCR. We have previously shown that plasma TNF- $\alpha$ is also elevated in PRRSV-inoculated gilts on GD 83, 90, and 97 (7, 14, and $21 \mathrm{dpi}$, respectively; treatment $\times$ time, $p<$ $0.0001)$ [45]. PRRSV infection during gestation results in increased incidences of abortion and premature delivery, and increased neonate mortality [40]. Here, maternal PRRSV infection increased piglet mortality, in agreement with reports of reproductive failure due to late-gestation PRRSV infection [63-65]. While transplacental fetal infection does occur, there was no significant effect of positive viral infection on any analyses in our model. Epidemiological studies assessing the risks from maternal infection for psychiatric disorders in offspring indicate that both pathogens which are transmissible to the fetus (rubella virus, cytomegalovirus, herpes simplex virus, and Toxoplasma gondii) and those that are nontransmissible (influenza virus) confer a risk [2, 66]; animal models strongly suggest that the maternal inflammatory response (i.e., cytokines such as IL-6 and IL-17a), and not the pathogen, drives the detrimental effects of MIA on the neurodevelopment and behavior of the offspring [13, 14, 19]. Thus, in our model, PRRSV infection serves to activate a maternal immune response comparable to that observed during human viral infections, such as influenza.

The brain weights of the viable piglets obtained from PRRSV-inoculated gilts at GD 111 were significantly reduced compared to those of the controls, indicating a targeted impact of maternal viral infection on brain development in the offspring. It is important to note that the piglets obtained from infected gilts had body weights comparable to those of the piglets obtained from control gilts, indicating that maternal infection did not cause intrauterine growth restriction (IUGR) or low-birth-weight fetuses. In most cases of IUGR, fetuses undergo an adaptive brain-sparing response that results in asymmetrical growth, wherein only body size, and not brain size, is reduced [67]. In our MIA model, there is no increase in incidences of IUGR or low-birth-weight piglets (seen here and previously [45]); to the contrary, it appears that MIA fetuses undergo inverse asymmetrical growth, wherein body weight is spared but brain weight is reduced.

The estimated neuronal cell density in the dentate gyrus and neuronal cell counts in the subiculum were significantly decreased in the GD 111 fetal brains exposed to maternal infection, which could partly explain the reduction in brain weight. One possibility that could account for this decrease would be a reduction in neurotrophic factors. Yet, NGF, BDNF, NTRK3, and NTF3 gene ex-
10

Dev Neurosci

DOI: $10.1159 / 000486850$
Antonson/Balakrishnan/Radlowski/Petr/ Johnson 


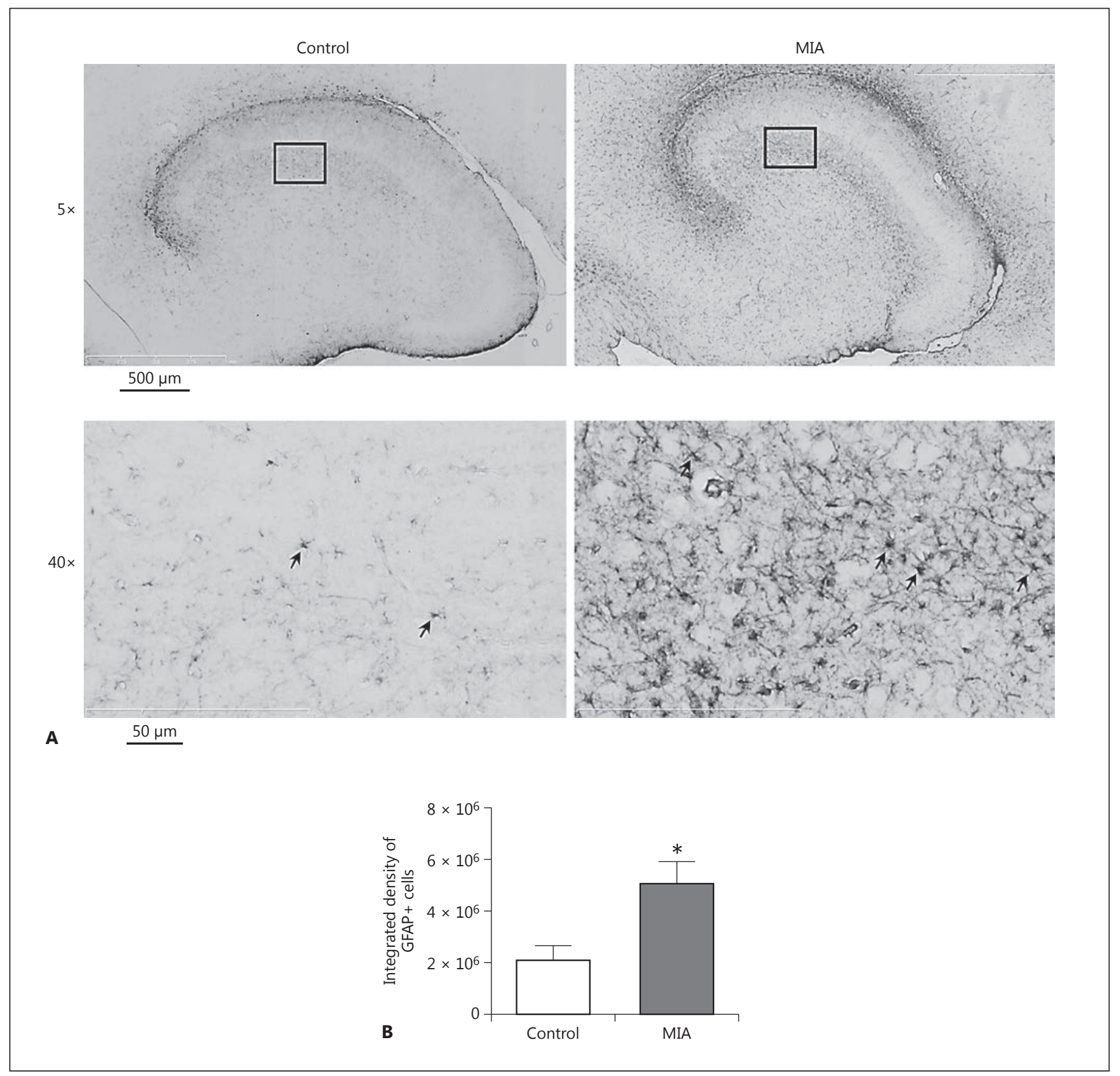

Fig. 5. Maternal viral infection resulted in an increased relative integrated density of GFAP staining in the hilar region of the hippocampus. A Representative images of GFAP-stained cells in the hilus of fetuses born to control and porcine reproductive and respiratory syndrome virus (PRRSV)-inoculated gilts at $5 \times$ and $40 \times$ magnifications. Arrows: representative, positively stained cells in each section. B An increased relative integrated density of GFAP staining was observed in the fetuses from PRRSV-infected gilts $(p<0.05)$. Data are represented as means \pm SEM. ${ }^{*} p<0.05$; controls: $n=7$; MIA: $n=11$. MIA, maternal immune activation. pression was unaltered by maternal infection at GD 111. The expression of markers involved in synaptic activity (synaptophysin) and pruning (TGF- $\beta$ and $\mathrm{CX}_{3} \mathrm{CL} 1[68$, 69]) was also unchanged. Interestingly, NGF expression was reduced in male fetuses compared to female fetuses, though there was no effect of MIA. We have previously observed sex differences in the hippocampus of neonatal piglets challenged with PRRSV, such that viral infection 
decreased the number of newly divided cells in males but not in females [47], though the expression of NGF was not investigated. In the hippocampus specifically, NGF has been implicated as a key player in plasticity and longterm potentiation throughout adult life [70]. Previous studies using two different rodent MIA models have reported an increased or unchanged expression of both NGF and BDNF in the fetal brain due to MIA. In a model using LPS, BDNF was only transiently increased 2-24 $\mathrm{h}$ after maternal LPS injection and returned to baseline levels by postnatal day (PD) 6; in contrast, NGF was unaltered in the hours following LPS injection but was increased at PD 6 [71]. When these markers were again examined by the same group using a poly I:C MIA model, differences in NGF and BDNF expression in the fetal brains were not present at any time point, pre- or postnatally [72]. Poly I:C is a viral mimetic immunogen that binds TLR3, so the maternal inflammatory mechanisms initiated during a poly $\mathrm{I}: \mathrm{C}$ challenge mimic what is seen during an active viral infection, such as with PRRSV. This could explain why no differences were observed here in the expression of either gene. As both NGF and BDNF are important regulators of neuronal survival and differentiation, future research designed to map the response of these markers over time, and across sex, to different MIA challenges is needed.

A 2-fold increase in expression of MBP was also observed in the fetal hippocampus at GD 111. This is in contrast with the current literature demonstrating impaired myelination in prenatal immune activation models, including studies focused on the hippocampus ([73-75], summarized by Boksa [76]). However, as MBP mRNA was only examined at one time point in the current study, we surmise that MBP gene expression may follow the same pattern as in previous studies if examined during acute maternal infection, and that the increase in expression observed 5 weeks after inoculation may be indicative of a compensatory mechanism, though further studies will need to be conducted to verify this hypothesis.

Evidence of astrocyte-specific gliosis was prominent at GD 111. GFAP gene expression was enriched in whole hippocampal tissue, and the relative integrated density of GFAP+ cells was significantly increased in the hilar region. Studies linking astrocytic activity to the etiology of poly I:C-specific MIA $[77,78]$ highlighted the ability of these glial cells, which express many of the same innate immune receptors as microglia and produce the same cytokines, to respond to MIA insults and participate in neurodevelopmental alterations. MIA models utilizing poly $\mathrm{I}: \mathrm{C}$ are arguably the most similar to the live viral infection used here, and it is plausible that virally mediated maternal infections follow similar etiologies in the fetal brain. Further research is needed to disentangle the specific involvement of fetal astrocytes in MIA and to separate their effects from those of microglia.

As established by Cunningham et al. [24], activation of microglial cells by MIA can result in excessive phagocytosis of neural precursor cells, which causes a decrease in neuronal numbers that endures postnatally. In our model, an indication of excessive neural progenitor cell phagocytosis was evident in the decreased estimated hippocampal neuronal cell density in MIA piglets, while microglial overactivation (measured by MHCII expression) was not apparent. A lack of microglial activation aligns with previous studies [30, 79-81], though we acknowledge that lasting microglial activation in this model cannot be ruled out solely by MHCII expression. Though MHCII is a widely used marker of classic microglial activation, microglia continuously take on varying states of activation that do not necessarily fall into classic or alternative categorizations [82-84] and resting or quiescent microglia still actively survey their environment and can engulf and clear parenchymal debris [85]. In agreement with the significant decrease in MHCII expression measured using flow cytometry, MHCII gene expression was significantly downregulated in whole hippocampal tissue as well. We have previously demonstrated that MHCII expression in isolated microglia from piglets of PRRSV-inoculated gilts is unchanged at PD 28 in our model, while lasting effects of MIA were evident in the emergence of altered social behaviors postnatally [45]. Gene expression of CD200 (the CD200R ligand expressed by neurons, astrocytes, or oligodendrocytes to signal microglial inhibition) tended to be upregulated, indicating a potential attenuation of microglial activation [86]; the expression of CD200R was unchanged.

Differences in hippocampal inflammatory gene expression indicated an enduring impact of maternal viral infection on the innate immune responses of the fetal CNS. In agreement with the altered fetal brain cytokine balance hypothesis [3], gene expression of TNF- $\alpha$ and IFN- $\gamma$ was significantly upregulated - along with a trend in upregulation of both IL- $1 \beta$ and STAT3 - due to MIA. These findings further indicate that any immediate markers of peripheral fetal inflammation are resolved before parturition in this model, but specific central markers of inflammation remain. IFN- $\gamma$, which induces the classic inflammatory microglial phenotype, can initiate the release of nitric oxide from activated microglia, leading to cellular damage to bystander cells like neu-
12

Dev Neurosci

DOI: $10.1159 / 000486850$
Antonson/Balakrishnan/Radlowski/Petr/ Johnson 
rons [87]. TNF- $\alpha$, which is preferentially derived from glia during neuroinflammatory states, is a powerful inhibitor of neurite outgrowth and branching [88]. Further in vitro work suggests that TNF- $\alpha$, IL- $1 \beta$, and IL-6 can directly impact neuron dendrite development such that the overall complexity of developing neurons is significantly reduced, similar to what is seen in disorders like schizophrenia [89]. The expression of STAT3, activated by IL- 6 signaling, tended to be increased. IL- 6 signaling has been shown to be necessary and sufficient for the behavioral and transcriptional abnormalities observed in models of MIA [13-15], and it likely potentiates peripheral IL-17a production and overexpression of IL-17Ra in the fetal brain - which was not measured here but results in robust alterations in cortical development and patterning [19].

Though there were no differences in the expression of NF- $\kappa B$, IL-6, IL-10, and $\mathrm{CX}_{3} \mathrm{CL} 1$ between the treatment groups at GD 111, this does not exclude the possibility of a transiently altered expression of these genes during peak maternal infection, which is no longer evident 35 days after inoculation. Indeed, Wu et al. [14] and Mouihate and Mehdawi [15] demonstrated an increased expression of IL-6, STAT3, and pSTAT3 in the fetal brain in the immediate hours following MIA, though these studies did not extend past $24 \mathrm{~h}$ after MIA induction. In fact, the most compelling and comprehensive evidence of the impact of MIA on fetal brain gene and protein expression to date has focused on the immediate time points following immune activation $[19,90]$, and several studies support the idea that neuroinflammation is resolved by the neonatal and postnatal periods $[79,81,91]$.

Interestingly, the expression of HSP70 and CCL2 was reduced in male fetuses but was not affected by maternal infection. HSP70, which has been linked to the pathophysiology of schizophrenia [92], is involved in protein folding and protects against both thermal and oxidative cellular stress. A reduction in HSP70 in brains of schizophrenics appears to contribute to reduced cognitive function [93], and the sexual dimorphism observed in the incidence of psychiatric disorders like schizophrenia and autism in human populations (higher in males [94, 95]) indicates that male piglets may be at a higher risk of developing behavioral abnormalities in our model. CCL2, also known as monocyte chemoattractant protein 1 (MCP-1), recruits monocytes and microglia [86] and induces microglial proliferation [96]. Although microglial proliferation in particular was not investigated here, Ki67 staining indicated that overall cell proliferation did not differ between the treatment groups. Work by Schwarz et al. [97] indicates that some chemokines, including CCL2, are upregulated in the developing hippocampus and cortex, and that they may be integral to recruiting and maintaining primitive and premature macrophages and microglia; however, no sex differences in CCL2 were reported. Thus, further investigation into the potential impact of sexual dimorphism in CCL2 expression, specifically within the context of MIA, is needed.

In conclusion, we demonstrated that maternal viral infection in swine increases fetal mortality, decreases fetal brain weight, and alters hippocampal development by decreasing estimated neuronal cell density and increasing GFAP expression immediately prior to parturition. Hippocampal gene expression revealed significant increases in TNF- $\alpha$ and IFN- $\gamma$, and a trending increase in IL-1 $\beta$ and STAT3, while the expression of other pro- and anti-inflammatory cytokines and downstream signaling molecules was unchanged, indicative of neuroinflammation that is partially resolved. However, an overall reduction in brain weight signifies that the lasting effects of MIA extend well past the hippocampus. An investigation of MHCII expression by microglial cells revealed a decrease in both protein and gene expression at GD 111, indicating that classic microglial activation, if present, may be resolved by this time. Future studies will aim to characterize fetal microglial activation during peak maternal inflammation and the concurrent impact on fetal neurodevelopment across multiple brain regions.

\section{Acknowledgments}

We would like to thank Marcus Lawson, Peng Ji, Matt Conrad, Jennifer Rytych, Brian Leyshon, Stephanie Matt, Elizabeth Bierman, Megan Caputo, Elizabeth Hogan, Tara Garcia, Emmanuelle Asrow, Brandi Burton, Emily Solan, Trisha Gibbons, Taylor Rietveld, Emily Rehm, Lee Jeongjae, Meghana Srinivasan, Micah Tryba, Jennifer Williams, and Jalisa Zimmerman for their help with swine care, cell counting, and microglial isolation procedures. We thank Dr. William Van Alstine for provision of PRRSV.

\section{Disclosure Statement}

The authors declare no conflicts of interest.

\section{Funding Sources}

This study was funded by NIH grant R01 HD069899 to R.W.J. 


\section{Author Contributions}

A.M.A. is responsible for acquisition of data, including the gilt IL-6 ELISA analysis; all statistical analyses; generation of figures; interpreting the data; and writing the final manuscript. B.B. is responsible for acquisition of data, including estimated neuronal cell counts and Ki-67 staining and quantification, and preparing a draft of the manuscript. E.C.R. is responsible for acquisition of data, including ELISAs, microglial cell isolation, staining, and flow cytometry, and the study design. G.P. is responsible for the study design and acquisition of data, including collecting gilt and fetal data. R.W.J. is responsible for conceptualizing the hypothesis and study design; interpreting the data; major edits and revisions to the manuscript; and funding the project. All authors contributed to editing and revising the manuscript.

\section{References}

$\checkmark 1$ Khandaker GM, Zimbron J, Lewis G, Jones $>13$ Smith SE, Li J, Garbett K, Mirnics K, PatterPB: Prenatal maternal infection, neurodevelopment and adult schizophrenia: a systematic review of population-based studies. Psychol Med 2013;43:239-257.

-2 Atladóttir HO, Thorsen P, Østergaard L, Schendel DE, Lemcke S, Abdallah M, Parner ET: Maternal infection requiring hospitalization during pregnancy and autism spectrum disorders. J Autism Dev Disord 2010;40: 1423-1430.

3 Meyer U, Feldon J, Yee BK: A review of the fetal brain cytokine imbalance hypothesis of schizophrenia. Schizophr Bull 2009;35:959972.

-4 Gayle DA, Beloosesky R, Desai M, Amidi F, Nuñez SE, Ross MG: Maternal LPS induces cytokines in the amniotic fluid and corticotropin releasing hormone in the fetal rat brain. Am J Physiol Regul Integr Comp Physiol 2004;286:R1024-R1029.

-5 Knuesel I, Chicha L, Britschgi M, Schobel SA, Bodmer M, Hellings JA, Toovey S, Prinssen EP: Maternal immune activation and abnormal brain development across CNS disorders. Nat Rev Neurol 2014;10:643-660.

-6 Estes ML, McAllister AK: Maternal immune activation: implications for neuropsychiatric disorders. Science 2016;353:772-777.

7 Dantzer R, Kelley KW: Twenty years of research on cytokine-induced sickness behavior. Brain Behav Immun 2007;21:153-160.

$\checkmark 8$ Mousa A, Bakhiet M: Role of cytokine signaling during nervous system development. Int $\mathrm{J}$ Mol Sci 2013;14:13931-13957.

-9 Burd I, Balakrishnan B, Kannan S: Models of fetal brain injury, intrauterine inflammation, and preterm birth. Am J Reprod Immunol 2012;67:287-294.

10 Pineda E, Shin D, You SJ, Auvin S, Sankar R, Mazarati A: Maternal immune activation promotes hippocampal kindling epileptogenesis in mice. Ann Neurol 2013;74:11-19.

-11 Malkova NV, Yu CZ, Hsiao EY, Moore MJ, Patterson PH: Maternal immune activation yields offspring displaying mouse versions of the three core symptoms of autism. Brain Behav Immun 2012;26:607-616.

12 Meyer U, Feldon J, Schedlowski M, Yee BK: Towards an immuno-precipitated neurodevelopmental animal model of schizophrenia. Neurosci Biobehav Rev 2005;29:913-947. son $\mathrm{PH}$ : Maternal immune activation alters fetal brain development through interleukin-6. J Neurosci 2007;27:10695-10702.

$\checkmark 14$ Wu WL, Hsiao EY, Yan Z, Mazmanian SK, Patterson PH: The placental interleukin-6 signaling controls fetal brain developmen and behavior. Brain Behav Immun 2017;62: 11-23.

15 Mouihate A, Mehdawi H: Toll-like receptor 4-mediated immune stress in pregnant rats activates STAT3 in the fetal brain: role of interleukin-6. Pediatr Res 2016;79:781-787.

16 Estes ML, McAllister AK: Maternal $\mathrm{T}_{\mathrm{H}} 17$ cells take a toll on baby's brain. Science 2016;351: 919-920.

17 Shin Yim Y, Park A, Berrios J, Lafourcade M, Pascual LM, Soares N, Yeon Kim J, Kim S, Kim H, Waisman A, Littman DR, Wickersham IR, Harnett MT, Huh JR, Choi GB: Reversing behavioural abnormalities in mice exposed to maternal inflammation. Nature 2017;549:482-487.

18 Kim S, Kim H, Yim YS, Ha S, Atarashi K, Tan TG, Longman RS, Honda K, Littman DR, Choi GB, Huh JR: Maternal gut bacteria promote neurodevelopmental abnormalities in mouse offspring. Nature 2017;549:528-532.

19 Choi GB, Yim YS, Wong H, Kim S, Kim H, Kim SV, Hoeffer CA, Littman DR, Huh JR: The maternal interleukin-17a pathway in mice promotes autism-like phenotypes in offspring. Science 2016;351:933-939.

20 Onore C, Careaga M, Ashwood P: The role of immune dysfunction in the pathophysiology of autism. Brain Behav Immun 2012;26:383392.

21 Monji A, Kato TA, Mizoguchi Y, Horikawa H, Seki Y, Kasai M, Yamauchi Y, Yamada S, Kanba S: Neuroinflammation in schizophrenia especially focused on the role of microglia. Prog Neuropsychopharmacol Biol Psychiatry 2013;42:115-121.

22 Morgan JT, Chana G, Pardo CA, Achim C, Semendeferi K, Buckwalter J, Courchesne E, Everall IP: Microglial activation and increased microglial density observed in the dorsolateral prefrontal cortex in autism. Biol Psychiatry 2010;68:368-376.

23 Morgan JT, Chana G, Abramson I, Semendeferi K, Courchesne E, Everall IP: Abnormal microglial-neuronal spatial organization in the dorsolateral prefrontal cortex in autism. Brain Res 2012;1456:72-81.

24 Cunningham CL, Martínez-Cerdeño V, Noctor SC: Microglia regulate the number of neural precursor cells in the developing cerebral cortex. J Neurosci 2013;33:4216-4233.

25 Pierre WC, Smith PL, Londono I, Chemtob S Mallard C, Lodygensky GA: Neonatal microglia: the cornerstone of brain fate. Brain Behav Immun 2017;59:333-345

26 Kettenmann $H$, Hanisch UK, Noda M, Verkhratsky A: Physiology of microglia. Physiol Rev 2011;91:461-553.

27 Kettenmann H, Kirchhoff F, Verkhratsky A: Microglia: new roles for the synaptic stripper. Neuron 2013;77:10-18.

28 Boche D, Perry VH, Nicoll JA: Review: activation patterns of microglia and their identification in the human brain. Neuropathol Appl Neurobiol 2013;39:3-18.

29 Matcovitch-Natan O, Winter DR, Giladi A Vargas Aguilar S, Spinrad A, Sarrazin S, BenYehuda H, David E, Zelada González F, Perrin P, Keren-Shaul H, Gury M, Lara-Astaiso D, Thaiss CA, Cohen M, Bahar Halpern K, Baruch K, Deczkowska A, Lorenzo-Vivas E, Itzkovitz S, Elinav E, Sieweke MH, Schwartz M, Amit I: Microglia development follows a stepwise program to regulate brain homeostasis. Science 2016;353:aad8670.

30 Smolders S, Smolders SM, Swinnen N, Gärtner A, Rigo JM, Legendre P, Brône B: Maternal immune activation evoked by polyinosinic:polycytidylic acid does not evoke microglial cell activation in the embryo. Front Cell Neurosci 2015;9:301.

- 31 Pratt L, Ni L, Ponzio NM, Jonakait GM: Maternal inflammation promotes fetal microglial activation and increased cholinergic expression in the fetal basal forebrain: role of interleukin-6. Pediatr Res 2013;74:393-401.

-32 Zhang Z, van Praag H: Maternal immune activation differentially impacts mature and adult-born hippocampal neurons in male mice. Brain Behav Immun 2015;45:60-70.

33 Oh-Nishi A, Obayashi S, Sugihara I, Minamimoto T, Suhara T: Maternal immune activation by polyriboinosinic-polyribocytidilic acid injection produces synaptic dysfunction but not neuronal loss in the hippocampus of juvenile rat offspring. Brain Res 2010;1363: 170-179. 
34 Conrad MS, Johnson RW: The domestic piglet: an important model for investigating the neurodevelopmental consequences of early life insults. Annu Rev Anim Biosci 2015;3: 245-264.

35 Dickerson JW, Dobbing J: Prenatal and postnatal growth and development of the central nervous system of the pig. Proc R Soc Lond B Biol Sci 1967;166:384-395.

- 36 Dobbing J, Sands J: Comparative aspects of the brain growth spurt. Early Hum Dev 1979; 3:79-83.

-37 Lind NM, Moustgaard A, Jelsing J, Vajta G, Cumming P, Hansen AK: The use of pigs in neuroscience: modeling brain disorders. Neurosci Biobehav Rev 2007;31:728-751.

38 Pond WG, Boleman SL, Fiorotto ML, Ho H, Knabe DA, Mersmann HJ, Savell JW, Su DR: Perinatal ontogeny of brain growth in the domestic pig. Proc Soc Exp Biol Med 2000;223: 102-108.

- 39 Kim TS, Benfield DA, Rowland RR: Porcine reproductive and respiratory syndrome virus-induced cell death exhibits features consistent with a nontypical form of apoptosis. Virus Res 2002;85:133-140.

40 Holtkamp DJ, Kliebenstein JB, Neumann EJ, Zimmerman JJ, Rotto HF, Yoder TK, Wang C, Yeske PE, Mowrer CL, Haley CA: Assessment of the economic impact of porcine reproductive and respiratory syndrome virus on United States pork producers. J Swine Health Prod 2013;21:72-84.

-41 Monto AS, Gravenstein S, Elliott M, Colopy $\mathrm{M}$, Schweinle J: Clinical signs and symptoms predicting influenza infection. Arch Intern Med 2000;160:3243-3247.

42 Conrad MS, Dilger RN, Johnson RW: Brain growth of the domestic pig (Sus scrofa) from 2 to 24 weeks of age: a longitudinal MRI study. Dev Neurosci 2012;34:291-298.

-43 Ji P, Schachtschneider KM, Schook LB, Walker FR, Johnson RW: Peripheral viral infection induced microglial sensome genes and enhanced microglial cell activity in the hippocampus of neonatal piglets. Brain Behav Immun 2016;54:243-251.

-44 Elmore MR, Burton MD, Conrad MS, Rytych JL, Van Alstine WG, Johnson RW: Respiratory viral infection in neonatal piglets causes marked microglia activation in the hippocampus and deficits in spatial learning. J Neurosci 2014;34:2120-2129.

-45 Antonson AM, Radlowski EC, Lawson MA, Rytych JL, Johnson RW: Maternal viral infection during pregnancy elicits anti-social behavior in neonatal piglet offspring independent of postnatal microglial cell activation. Brain Behav Immun 2017;59:300-312.

46 Liu CH, Chaung HC, Chang HL, Peng YT, Chung WB: Expression of Toll-like receptor mRNA and cytokines in pigs infected with porcine reproductive and respiratory syndrome virus. Vet Microbiol 2009;136:266276.
47 Conrad MS, Harasim S, Rhodes JS, Van Alstine WG, Johnson RW: Early postnatal respiratory viral infection alters hippocampal neurogenesis, cell fate, and neuron morphology in the neonatal piglet. Brain Behav Immun 2015;44:82-90.

48 Livak KJ, Schmittgen TD: Analysis of relative gene expression data using real-time quantitative PCR and the $2^{-\Delta \Delta C_{\mathrm{T}}}$ method. Methods 2001;25:402-408.

49 Pilati N, Barker M, Panteleimonitis S, Donga R, Hamann M: A rapid method combining Golgi and Nissl staining to study neuronal morphology and cytoarchitecture. J Histochem Cytochem 2008;56:539-550.

50 Mancuso R, Oliván S, Rando A, Casas C, Osta R, Navarro X: Sigma-1R agonist improves motor function and motoneuron survival in ALS mice. Neurotherapeutics 2012;9:814826.

-51 Moraga A, Pradillo JM, Cuartero MI, Hernández-Jiménez M, Oses M, Moro MA, Lizasoain I: Toll-like receptor 4 modulates cell migration and cortical neurogenesis after focal cerebral ischemia. FASEB J 2014;28:4710-4718.

52 Penas C, Casas C, Robert I, Forés J, Navarro $\mathrm{X}$ : Cytoskeletal and activity-related changes in spinal motoneurons after root avulsion. J Neurotrauma 2009;26:763-779.

53 Moreno-Igoa M, Calvo AC, Penas C, Manzano R, Oliván S, Muñoz MJ, Mancuso R, Zaragoza $\mathrm{P}$, Aguilera J, Navarro X, Osta Pinzolas $\mathrm{R}$ : Fragment $\mathrm{C}$ of tetanus toxin, more than a carrier. Novel perspectives in non-viral ALS gene therapy. J Mol Med (Berl) 2010;88:297308.

54 Radlowski EC, Conrad MS, Lezmi S, Dilger RN, Sutton B, Larsen R, Johnson RW: A neonatal piglet model for investigating brain and cognitive development in small for gestational age human infants. PLoS One 2014;9: e91951.

55 Giovanoli S, Meyer U: Response to comment on "Stress in puberty unmasks latent neuropathological consequences of prenatal immune activation in mice." Science 2013;340: 811.

56 Ford AL, Goodsall AL, Hickey WF, Sedgwick JD: Normal adult ramified microglia separated from other central nervous system macrophages by flow cytometric sorting. Phenotypic differences defined and direct ex vivo antigen presentation to myelin basic proteinreactive CD4+ T cells compared. J Immunol 1995; 154:4309-4321.

57 Henry CJ, Huang Y, Wynne AM, Godbout JP: Peripheral lipopolysaccharide (LPS) challenge promotes microglial hyperactivity in aged mice that is associated with exaggerated induction of both pro-inflammatory IL- $1 \beta$ and anti-inflammatory IL-10 cytokines. Brain Behav Immun 2009;23:309-317.

58 Nair A, Bonneau RH: Stress-induced elevation of glucocorticoids increases microglia proliferation through NMDA receptor activation. J Neuroimmunol 2006;171:72-85.
59 Dawson H: A Comparative assessment of the pig, mouse and human genomes; in McAnulty PA, Dayan AD, Ganderup NC, Hastings KL (eds): The Minipig in Biomedical Research. Boca Raton, CRC Press, 2011, pp 323-342.

60 Dawson HD, Loveland JE, Pascal G, Gilbert JG, Uenishi H, Mann KM, Sang Y, Zhang J, Carvalho-Silva D, Hunt T, et al: Structural and functional annotation of the porcine immunome. BMC Genomics 2013;14:332.

61 Zschaler J, Schlorke D, Arnhold J: Differences in innate immune response between man and mouse. Crit Rev Immunol 2014;34:433-454.

-62 Seok J, Warren HS, Cuenca AG, Mindrinos MN, Baker HV, Xu W, Richards DR, McDonald-Smith GP, Gao H, Hennessy L, et al; Inflammation and Host Response to Injury, Large Scale Collaborative Research Program: Genomic responses in mouse models poorly mimic human inflammatory diseases. Proc Natl Acad Sci USA 2013;110:3507-3512.

- 63 Ladinig A, Ashley C, Detmer SE, Wilkinson JM, Lunney JK, Plastow G, Harding JC: Maternal and fetal predictors of fetal viral load and death in third trimester, type 2 porcine reproductive and respiratory syndrome virus infected pregnant gilts. Vet Res 2015;46:107.

64 Cheon DS, Chae C: Distribution of porcine reproductive and respiratory syndrome virus in stillborn and liveborn piglets from experimentally infected sows. J Comp Pathol 2001; 124:231-237.

-65 Kranker S, Nielsen J, Bille-Hansen V, Bøtner A: Experimental inoculation of swine at various stages of gestation with a Danish isolate of porcine reproductive and respiratory syndrome virus (PRRSV). Vet Microbiol 1998; 61:21-31.

66 Brown AS: Prenatal infection as a risk factor for schizophrenia. Schizophr Bull 2006;32: 200-202.

67 Brodsky D, Christou H: Current concepts in intrauterine growth restriction. J Intensive Care Med 2004;19:307-319.

68 Bialas AR, Stevens B: TGF- $\beta$ signaling regulates neuronal C1q expression and developmental synaptic refinement. Nat Neurosci 2013; 16:1773-1782.

69 Paolicelli RC, Bolasco G, Pagani F, Maggi L, Scianni M, Panzanelli P, Giustetto M, Ferreira TA, Guiducci E, Dumas L, Ragozzino D, Gross CT: Synaptic pruning by microglia is necessary for normal brain development. Science 2011;333:1456-1458.

70 Conner JM, Franks KM, Titterness AK, Russell K, Merrill DA, Christie BR, Sejnowski TJ, Tuszynski MH: NGF is essential for hippocampal plasticity and learning. J Neurosci 2009;29:10883-10889.

71 Gilmore JH, Jarskog LF, Vadlamudi S: Maternal infection regulates BDNF and NGF expression in fetal and neonatal brain and maternal-fetal unit of the rat. J Neuroimmunol 2003;138:49-55. 
72 Gilmore JH, Jarskog LF, Vadlamudi S: Maternal poly I:C exposure during pregnancy regulates TNFa, BDNF, and NGF expression in neonatal brain and the maternal-fetal unit of the rat. J Neuroimmunol 2005;159:106-112.

-73 Györffy BA, Gulyássy P, Gellén B, Völgyi K, Madarasi D, Kis V, Ozohanics O, Papp I, Kovács P, Lubec G, Dobolyi Á, Kardos J, Drahos L, Juhász G, Kékesi KA: Widespread alterations in the synaptic proteome of the adolescent cerebral cortex following prenatal immune activation in rats. Brain Behav Immun 2016;56:289-309.

-74 Farrelly L, Föcking M, Piontkewitz Y, Dicker P, English J, Wynne K, Cannon M, Cagney G, Cotter DR: Maternal immune activation induces changes in myelin and metabolic proteins, some of which can be prevented with risperidone in adolescence. Dev Neurosci 2015;37:43-55.

75 Makinodan M, Tatsumi K, Manabe T, Yamauchi T, Makinodan E, Matsuyoshi H, Shimoda S, Noriyama Y, Kishimoto T, Wanaka A: Maternal immune activation in mice delays myelination and axonal development in the hippocampus of the offspring. J Neurosci Res 2008;86:2190-2200.

76 Boksa P: Effects of prenatal infection on brain development and behavior: a review of findings from animal models. Brain Behav Immun 2010;24:881-897.

-77 Bernstein HG, Piontkewitz Y, Keilhoff G: Commentary: maternal immune activation evoked by polyinosinic: polycytidylic acid does not evoke microglial cell activation in the embryo. Front Cell Neurosci 2016;10:41.

78 Ibi D, Yamada K: Therapeutic targets for neurodevelopmental disorders emerging from animal models with perinatal immune activation. Int J Mol Sci 2015;16:28218-28229.

-79 Giovanoli S, Notter T, Richetto J, Labouesse MA, Vuillermot S, Riva MA, Meyer U: Late prenatal immune activation causes hippocampal deficits in the absence of persistent inflammation across aging. J Neuroinflammation 2015;12:221.
80 Giovanoli S, Weber-Stadlbauer U, Schedlowski M, Meyer U, Engler H: Prenatal immune activation causes hippocampal synaptic deficits in the absence of overt microglia anomalies. Brain Behav Immun 2016;55:2538.

81 Missault S, Van den Eynde K, Vanden Berghe W, Fransen E, Weeren A, Timmermans JP, Kumar-Singh S, Dedeurwaerdere S: The risk for behavioural deficits is determined by the maternal immune response to prenatal immune challenge in a neurodevelopmental model. Brain Behav Immun 2014;42:138146.

82 Ransohoff RM: A polarizing question: do M1 and M2 microglia exist? Nat Neurosci 2016; 19:987-991.

83 Town T, Nikolic V, Tan J: The microglial “activation" continuum: from innate to adaptive responses. J Neuroinflammation 2005;2:24.

84 Scheffel J, Regen T, Van Rossum D, Seifert S, Ribes S, Nau R, Parsa R, Harris RA, Boddeke HW, Chuang HN, Pukrop T, Wessels JT, Jürgens T, Merkler D, Brück W, Schnaars M, Simons M, Kettenmann H, Hanisch UK: Tolllike receptor activation reveals developmental reorganization and unmasks responder subsets of microglia. Glia 2012;60:1930-1943.

85 Nimmerjahn A, Kirchhoff F, Helmchen F: Resting microglial cells are highly dynamic surveillants of brain parenchyma in vivo. Science 2005;308:1314-1318.

86 Perry VH, Holmes C: Microglial priming in neurodegenerative disease. Nat Rev Neurol 2014;10:217-224.

87 Moss DW, Bates TE: Activation of murine microglial cell lines by lipopolysaccharide and interferon $-\gamma$ causes NO-mediated decreases in mitochondrial and cellular function. Eur J Neurosci 2001;13:529-538.

88 Neumann H, Schweigreiter R, Yamashita T, Rosenkranz K, Wekerle H, Barde YA: Tumor necrosis factor inhibits neurite outgrowth and branching of hippocampal neurons by a rhodependent mechanism. J Neurosci 2002;22: 854-862.
89 Gilmore JH, Jarskog LF, Vadlamudi S, Lauder JM: Prenatal infection and risk for schizophrenia: IL-1 $\beta$, IL-6, and TNF $\alpha$ inhibit cortical neuron dendrite development. Neuropsychopharmacology 2004;29:1221-1229.

90 Lombardo MV, Moon HM, Su J, Palmer TD, Courchesne E, Pramparo T: Maternal immune activation dysregulation of the fetal brain transcriptome and relevance to the pathophysiology of autism spectrum disorder. Mol Psychiatry 2017, Epub ahead of print.

91 Arsenault D, St-Amour I, Cisbani G, Rousseau LS, Cicchetti F: The different effects of LPS and poly I:C prenatal immune challenges on the behavior, development and inflammatory responses in pregnant mice and their offspring. Brain Behav Immun 2014;38:77-90.

92 Patel S, Sharma D, Kalia K, Tiwari V: Crosstalk between endoplasmic reticulum stress and oxidative stress in schizophrenia: the dawn of new therapeutic approaches. Neurosci Biobehav Rev 2017;83:589-603.

93 Leonidas M: The distribution of the stress protein HSP70 in the cerebellum of patients with schizophrenia. Neurosci Med 2012;3: 368-373.

94 Iacono WG, Beiser M: Are males more likely than females to develop schizophrenia? Am J Psychiatry 1992;149:1070-1074.

$>95$ Developmental Disabilities Monitoring Network Surveillance Year 2010 Principal Investigators; Centers for Disease Control and Prevention (CDC): Prevalence of autism spectrum disorder among children aged 8 years - Autism and Developmental Disabilities Monitoring Network, 11 Sites, United States, 2010. MMWR Surveill Summ 2014; 63:1-21.

>96 Hinojosa AE, Garcia-Bueno B, Leza JC, Madrigal JL: CCL2/MCP-1 modulation of microglial activation and proliferation. J Neuroinflammation 2011;8:77.

97 Schwarz JM, Sholar PW, Bilbo SD: Sex differences in microglial colonization of the developing rat brain. J Neurochem 2012;120:948963 